\title{
O DESENVOLVIMENTO DA EDUCAÇÃO ESPECIAL SOB A ÓTICA DA EDUCAÇÃO INCLUSIVA
}

\author{
Célia Aparecida Conceição ${ }^{1}$ \\ Professor Doutor Carlos Luiz Pereira²
}

\section{Resumo}

Considerando o cenário de atualização constante das políticas públicas em defesa e manutenção dos direitos dos indivíduos com necessidades especiais, o presente artigo tem por objetivo auxiliar na compreensão da educação especial sob a ótica da educação exclusiva, apontando as responsabilidades de cada sujeito envolvido no processo. Para o desenvolvimento do trabalho foi escolhida a pesquisa bibliográfica, 25 títulos, pertinentes ao tema, foram selecionados para compor a discussão proposta. Entendemos por educação inclusiva aquela que constrói um ambiente de educação que trata diferença e igualdade como princípios inseparáveis e que em seu universo encontramos a educação especial, que se faz presente em todas as etapas escolares, e tem por responsabilidade ofertar atendimento especializado, permitindo ao docente com necessidade especial o desenvolvimento integral no processo de ensino aprendizagem, cabendo aos educadores estarem atualizados quanto ao tema e novas práticas e ao ambiente escolar se fazer acessível, oferecendo ao aluno a possibilidade de inserção em turmas de ensino regular e mais do que isso, tornar o aluno parte integrante da comunidade escolar.

Palavras-chave: Educação Especial. Educação Inclusiva. Inclusão. Inclusão Escolar.

\section{INTRODUÇÃO}

O desafio global, no que tange à educação, é o da construção de um sistema de educação que abranja e preserve o direito da população, inclusive do atendimento educacional especializado (SOBRINHO, PANTALEÃO e SÁ, 2016).

\footnotetext{
${ }^{1}$ Mestranda em Educação - Facultad Interamericana de Ciencias Sociales: celia_apcom@hotmail.com

${ }^{2}$ Professor Doutor; Orientador
} 
O processo de inclusão de sujeitos com necessidades especiais nas escolas constrói-se no Brasil como movimento ético sustentado na garantia da educação como direito assegurado pela Constituição (VIEIRA; RAMOS, 2018).

$\mathrm{O}$ atendimento educacional especializado foi constituído em paralelo a educação regular, ofertada aos sujeitos que não apresentavam características definidas como "anormais". Criando um viés de atuação especializada, o da educação especial, que por diversas vezes não dialogava com a educação regular. Essa separação, por anos, foi caracterizada, principalmente, pelo atendimento dos alunos com necessidades especiais em instituições de ensino específicas, separadas de instituições de ensino regulares (KASSAR, 2011).

Essa necessidade de identificar o que era "anormal", para separar da educação formal, surgiu com a prática da ciência médico-pedagógica (Santos, 2012). Em que, para pesquisadores da época, como Ugo Pizzoli (1863-1934), por exemplo, a criança caracterizava-se por seu aspecto externo - vestimenta, maneira de se portar e relacionar, características físicas - e que esse aspecto revelava o aspecto psicológico da criança, dando ao educador, como prioridade identificar a tipo inteligente normal e o tipo inteligente débil de espírito caracterizado por atrasos no desenvolvimento cognitivo e intelectual (PIZOLLI, 1914).

Nesse contexto, os órgãos públicos recorreram à justificativa dada pela ciência médico-pedagógica para a segregação dos alunos considerados anormais, direcionando esses para instituições de atendimento especializado. Nessa mesma época, início dos anos 1900, estava ocorrendo o processo de crescimento das cidades, com a migração dos agricultores, o que causou um aumento considerável no número de matrículas escolares, partindo do Estado, que percebeu o aumento da população menos abastarda nas escolas, a necessidade de justificar a segregação dos alunos de maneira legal (VITTA, SILVA e ZINIOLO, 2016; SOBRINHO, PANTALEÃO e SÁ, 2016; SANTOS, 2012; RIBEIRO, 2009).

\section{Art. 826}

As escolas de débeis físicos se destinam às crianças desnutridas ou em crescimento em atraso as quais convenha regime especial de trabalho escolar, com o fim de reintegrá-las na normalidade física (DECRETO 5.884, de 1933) 
Apenas na década de 70 que a concepção de inclusão chega ao Brasil, e vem para contrapor os modelos separatistas, defendendo o entendimento de que devem ser possibilitadas ao sujeito com deficiência condições de vida que o aproximem ao máximo das condições de um sujeito que não possui deficiência, norteando, dessa forma, os valores das políticas públicas nos anos 80, que primavam pela integração e normalização (MANTOAN, 2006; RIOBEIRO, 2009).

Caminhando em busca da integração e inclusão, em 25 de junho de 2014, o Congresso Nacional de Educação, aprova o Plano Nacional de Educação, que tem vigência de dez anos e traz em sua meta de número quatro - estabelecimento da universalização do acesso à educação básica, resguardando o direito de atendimento integral e especializado aos sujeitos de 4 a 17 anos que possuem quaisquer necessidades especiais (SOBRINHO, PANTALEÃO e SÁ, 2016).

Diante a mudança no quadro das políticas públicas, estabelecendo sempre a constante preocupação em garantir o direito à educação aos alunos com necessidades especiais e a busca pela compreensão do papel de cada ator no processo de inclusão quando se trata de educação especial, o presente artigo tem por objetivo auxiliar na compreensão da educação especial sob a ótica da educação exclusiva, apontando as responsabilidades de cada sujeito envolvido no processo.

Essa compreensão torna-se importante ao passo que o ambiente escolar recebe alunos com necessidades especiais e esses tem direito resguardado a educação integral, com todas as nuances e recursos demandados para qualquer outro aluno, desta forma, compreender a educação especial no que tange a inclusão, permite que nos percebamos parte do processo de tornar o aluno parte da comunidade escolar.

\section{FUNDAMENTAÇÃO TEÓRICA}

\subsection{BREVE TRAJETÓRIA DA EDUCAÇÃO ESPECIAL}

Ao revisar a história, percebe-se que as pessoas com deficiência sempre foram postas às margens. Na época pré-cristã os sujeitos deficientes eram negligenciados, posteriormente, na antiguidade, muitos indivíduos com 
deficiência foram abandonados ou executados (SANTOS, 2006; CAMARGO, 2017; BORGES, 2015).

Já na Idade Média, as pessoas com deficiência passaram por duas situações distintas, em um momento eram consideradas sagradas e deveriam ser respeitadas e cuidadas, porém em outros momentos a deficiência de seus corpos era atribuída à presença do maligno e, por isso, deviam ser executadas. Esse momento da história foi marcado pela ambiguidade na compreensão das deficiências, tenso sua compreensão permeada sempre pela ótica sobrenatural (CARMARGO, 2017; BORGES; 2015).

Essa compreensão sobre a deficiência, relacionada ao sobrenatural, deu lugar a compreensão médica, no século XVI, e a deficiência passa a ser analisada enquanto doença. Os indivíduos que possuíam qualquer deficiência eram tratados com propósito curativo. Essa mudança não foi capaz de promover mudança na maneira de compreender e aceitar os "diferentes", esses ainda eram segregados e sem receber devida dedicação do Estado e familiares (RIBEIRO, 2009; SOBRINO, PANTALEÃO e SÁ, 2016; CAMARGO, 2017).

Nessa realidade, os deficientes eram asilados em hospitais, psiquiátricos ou não, com a justificativa da manutenção do equilíbrio social. Amenizando o incômodo, manifestado pela sociedade, sobre o que era diferente dos padrões considerados normais (RIBEIRO, 2009; SOBRINO, PANTALEÃO e SÁ, 2016; CAMARGO, 2017).

Com o caminhar da história, nos séculos XVIII e XIX, foram criadas instituições a fim de ofertar educação aos indivíduos com deficiência fora do ambiente formal de ensino, dando início ao que conhecemos hoje por educação especial, neste momento as ações produzidas em prol da educação especial eram desenvolvidas por profissionais médicos, nessa época, as instituições especializadas eram caracterizadas pelo atendimento assistencial, não voltado especificamente para práticas educacionais (RIBEIRO, 2009; SOBRINO, PANTALEÃO e SÁ, 2016; CAMARGO, 2017).

Avançando com a história da educação especial e se tratando, especificamente, do Brasil, o movimento em benefício da educação especial teve seu reflexo com a fundação do Imperial Instituto dos Meninos Cegos (1854), atual Instituto Benjamin Constant, e do Imperial Instituto de SurdosMudos (1857), atual Instituto Nacional de Educação de Surdos, ambos criados 
por Dom Pedro II e que estão em funcionamento até hoje. A atenção dispensada aos sujeitos com deficiência teve seu início na transição do Brasil Império para República, porém a educação especial, de fato, e a inserção desses alunos com deficiência foram iniciadas apenas no século $X X$ (JANNUZZI, 1992).

Entre os anos 1920 e 1930 houve um movimento, denominado Escola Nova, que tinha por objetivo amenizar a disparidade social, foram inseridas práticas pedagógicas fundamentadas em educadores que lidavam com indivíduos portadores de necessidades especiais. Esse crescimento das classes de educação especial, funcionou como paliativo para o fato de as escolas não estarem preparadas para lidar com as necessidades individuais de cada aluno, eram classes que tinham a função separatista, de segregar os alunos que não acompanhavam os demais nas classes regulares de ensino (JANNUZZI, 1992; HARLOS, DENAIR e ORLANDO, 2014; VIEIRA e RAMOS, 2018; CARAMORI e DELLA'ACQUA, 2015).

Foi apenas em nos anos 70 que um novo conceito de inclusão surgiu, contrapondo os modelos separatistas, que marginalizavam os alunos deficientes, defendendo a necessidade de se dar oportunidade de meios que possibilitassem 0 desenvolvimento integral do processo de ensino aprendizagem de qualquer aluno, independente da necessidade individual, dando início a um novo cenário de políticas públicas, orientado pelo valor da integração (RIBEIRO, 2009; SOBRINO, PANTALEÃO e SÁ, 2016; CAMARGO, 2017).

E a partir desse momento, encontros internacionais foram organizados para a discussão da garantia dos direitos dos indivíduos com necessidades especiais, com adoção de amparo legal para a manutenção da garantia do atendimento a esses cidadãos, época essa, equivalente ao final da ditadura militar e da redação de uma nova constituição, a Constituição Federal de 1988, que garantia a população uma série de direitos, incluindo o direito à educação (SANTOS, 2006; CAMARGO, 2017; BORGES, 2015). 


\subsection{A EDUCAÇÃO INCLUSIVA E A EDUCAÇÃO ESCOLAR PARA ALUNOS} COM NECESSIDADES ESPECIAIS

O modelo de inclusão pode ser aplicado nos mais diversos ambientes e as pessoas com necessidades especiais, no que diz respeito ao processo de inclusão, tem suas peculiaridades legitimadas e respeitadas. E considerando 0 contexto inclusivo, esse grupo participa efetivamente do processo de transformação social que visa acolher e participar os sujeitos com necessidades especiais (EDITORIAL, 2017; SOBRINO, PANTALEÃO e SÁ, 2016).

No Brasil, o esboço global que sustenta a aplicação da legislação básica de inclusão da pessoa com deficiência discute de maneira clara a concepção da política de inclusão (BRASIL, 2015). O esboço global, definido como "desenho universal" é estabelecido, na Lei Brasileira de Inclusão da Pessoa com Deficiência, por conceito, como:

Art. 102

"[...] desenho universal: concepção de produtos, ambientes, programas e serviços a serem usados por todas as pessoas, sem necessidade de adaptação ou de projeto específico, incluindo os recursos de tecnologia assistiva." (BRASIL, 2015, p. 29).

Não há coerência em preparar um aluno com deficiência apenas para o ambiente escolar, visto que, para além dos ambientes formais serão encontradas barreiras potencialmente exclusivas, entendendo, por isso, que a inclusão se trata de uma ação social aplicada nos mais diversos espaços e realidades, mas, primordialmente na maneira de se relacionar com o meio externo e com si mesmo (VIEIRA e RAMOS, 2018; CARAMORI e DELLA'ACQUA, 2015; EDITORIAL, 2017).

$\mathrm{Na}$ educação, especificamente, abordar as concepções de identidade, diversidade e diferença se trata do passo inicial para a estruturação de métodos e rotinas que sejam efetivas para satisfazerem as particularidades de cada estudante, afim de proporcional o desenvolvimento integral do processo de ensino aprendizagem (SASSAKI, 2005; SANCHEZ, 2005; CASTRO, ALMEIDA e FERREIRA, 2010; BATISTA e EUNUMO, 2004).

A educação regular, construída no ambiente escolar, vai além do simples papel de promover o processo de ensino aprendizagem, é responsável por estimular o convívio com o outro, com o diferente e o respeito pela 
diferença. Introduz o aluno ao ambiente regado de diversidade, fazendo evidenciar a característica própria de cada sujeito e a necessidade do trabalho com o coletivo e com o individual. Essas características, além de impressionantes, desafiam diariamente a educação e educadores para que promovam o desenvolvimento integral de cada aluno (SANTOS, 2012; SANCHEZ, 2005; CASTRO, ALMEIDA e FERREIRA, 2010; BATISTA e EUNUMO, 2004).

Nesse contexto, a educação inclusiva tem por papel induzir à construção de metodologias que possibilitem a cada aluno a garantia da educação escolar regular, independente se o discente apresenta, ou não, alguma necessidade especial, tornando as instituições especializadas rede de apoio para suporte quando a escola formal não for suficiente para atender a demanda requerida por determinado aluno (SANTOS, 2012; SANCHEZ, 2005; CASTRO, ALMEIDA e FERREIRA, 2010; BATISTA e EUNUMO, 2004; MANTOAN, 2006).

Tendo em vista que o ambiente escolar tem por obrigação acolher qualquer aluno, mesmo quando há a necessidade de adaptação já que deve ser considerado que a diferença do ser humano é algo natural, a educação inclusiva surge com princípio de estabelecer nas instituições escolares a reflexão e ação sobre a necessidade de integrar os alunos com necessidades especiais em um maior número de atividades possíveis, para que, em sua particularidade, possam avanças com seu desenvolvimento psicológico, cognitivo e social. A inclusão não está pautada no vencimento dos obstáculos e sim no desenvolvimento integral do aluno (SANTOS, 2012; SASSAKI, 2005).

Nesse cenário, o educador é o responsável por proporcionar, em sala de aula, situações que fomentem o crescimento integral do aluno, não o segregando ou privilegiando em virtude de sua necessidade especial (CASTRO, ALMEIRA e FERREIRA, 2010; SOBRINO, PANTALEÃO e SÁ, 2016).

\section{METODOLOGIA}

A metodologia escolhida para o desenvolvimento desse artigo foi a pesquisa bibliográfica, que, de acordo com Gil (2002, p.45), trata-se de uma 
pesquisa "desenvolvida com base em materiais já elaborados, sua principal vantagem está no fato de permitir ao pesquisador a cobertura de uma gama de fenômenos mais ampla".

Não se limita a transcrição do que já foi produzido sobre determinado tema, vai além disso, permite a discussão do assunto escolhido sob um novo olhar, uma nova abordagem, culminando em discussões atuais e inovadas (MARCONI e LAKATOS, 2009).

Os dados foram recolhidos de bancos de publicações cientificamente reconhecidos e pertinentes à área. Após análise referente ao tema - $\mathrm{O}$ desenvolvimento da Educação Especial sob a Ótica da Educação Inclusiva 25 produções foram selecionadas para a construção dos tópicos propostos.

As publicações de Vitta, Silva e Ziniolo (2016), Sobrinho, Pantaleão e Sá (2016), Santos (2012), Ribeiro (2009), Kassar (2011), Harlos, Denair e Orlando (2014), Vieira e Ramos (2018), Caramori e Della'acqua (2015) e Camargo (2017), foram algumas das produções selecionadas para constituir a discussão estabelecida para esse artigo.

\section{EDUCAÇÃO ESPECIAL SOB A ÓTICA DA EDUCAÇÃO INCLUSIVA}

A educação inclusiva advém de um movimento global que tem como pilares os aspectos políticos, culturais, sociais e pedagógicos. Surgiu para defender a garantia do direito a educação e de o aluno fazer parte efetivamente da comunidade escolar, não permitindo tipo algum de segregação ou marginalização. Trata-se de um modelo de educação que tem como base a compreensão dos direitos humanos, vislumbrando conjuntamente os conceitos de igualdade e diferença, discutindo a necessidade de oferta em equivalência de educação, possibilidade e oportunidade a todos os alunos (BRASIL, 2007; CASTRO, ALMEIRA e FERREIRA, 2010; SOBRINO, PANTALEÃO e SÁ, 2016).

Por longos anos a compreensão limitada acerca da educação especial, levou à crença que o atendimento dos alunos com necessidades especiais em instituições especializadas e fora do ambiente educacional regular era a estratégia acertada para promover a educação escolar desses discentes. Essa 
realizada vem sendo alterada com as discussões propostas no campo da educação sobre inclusão, direitos humanos, legislação e práticas educacionais, que apontam cada vez mais para a necessidade de reformulação do ambiente escolar regular (EDITORIAL, 2017; BRASIL, 2007; BRASIL, 2010).

A Declaração de Salamanca (1994) declara que as escolas de ensino regular com norte inclusivo são as instituições mais competentes para contender ações de discriminação e que os estudantes com necessidades especiais tem o direito ao ensino regular, devendo as instituições de ensino acolherem todos os alunos independentemente de suas peculiaridades e necessidades (BRASIL, 2006; BRASIL, 2007; CASTRO, ALMEIRA e FERREIRA, 2010).

E a partir desse marco histórico, a concepção de "necessidade especial" passa a ser difundida ressaltando a necessidade do diálogo entre as especificidades de cada aluno e o ambiente escolar e fora da escola. Contudo, mesmo com toda discussão acerca do tema, e com o apontamento para a necessidade da construção de um ambiente escolar prioritariamente inclusivo, ainda existem entraves e o objetivo principal ainda não foi totalmente alcançado pelas políticas educacionais aplicadas (BRASIL, 2007; CASTRO, ALMEIRA e FERREIRA, 2010).

Sob o prisma da educação inclusiva, a educação especial passa a compor a recomendação pedagógica da escola regular, estimulando o atendimento aos alunos com qualquer tipo de necessidade especial, orientando para o atendimento simultâneo com o ensino regular, visando a formação integral do aluno (SANTOS, 2012; SANCHEZ, 2005; CASTRO, ALMEIDA e FERREIRA, 2010; BATISTA e EUNUMO, 2004; MANTOAN, 2006).

A educação especial norteia as práticas para que o aluno seja atendido em suas singularidades, no ambiente escolar formal, e estabelece as redes de apoio, a educação continuada dos docentes, bem como os recursos e serviços necessários para a promoção das práticas inclusivas (KASSAR, 2011; CASTRO, ALMEIDA e FERREIRA, 2010; CAMARGO, 2017).

Segundo Camargo (2017), as produções mais atuais, que discutem a educação especial, evidenciam que qualquer conceito referente às necessidades especiais deve ser contextualizado, não ficando limitado apenas a singularidade de uma deficiência, transtorno, síndrome ou aptidão. A 
dinâmica produzida pela convivência social muda constantemente as pessoas e o meio em que vivem, evidenciando a necessidade de uma atuação pedagógica que reforce a aprendizagem em um ambiente diverso e plural (CAMARGO, 2017; KASSAR, 2011).

A educação especial é uma vertente de ensino que percorre todas as instâncias e fases do ensino regular e tem por papel empreender o atendimento educacional especializado, identificando e constituindo meios para promover o processo de ensino aprendizagem de alunos com necessidades especiais nas turmas regulares do ensino formal (KASSAR, 2011; CASTRO, ALMEIDA e FERREIRA, 2010; CAMARGO, 2017).

Essa realidade exige uma prática pedagógica dinâmica, que se atente tanto ao nível basal de conhecimento do estudante, quanto ao seu progresso com o que diz respeito ao processo de ensino aprendizagem, representando um processo formativo que avalia o progresso do estudante ao longo de seu desenvolvimento e dá ferramentas para ajustes dos métodos intervencionistas utilizados pelo educador. O professor é responsável por desenvolver ações que potencialize o processo de ensino aprendizagem, considerando que, na perspectiva das necessidades especiais, alguns estudantes necessitarão extensão do prazo para desenvolvimento de alguma atividade ou a utilização de alguma linguagem específica (Linguagem Brasileira de Sinais, Braille) ou de tecnologia como aliadas do processo de ensino (BRASIL, 2007; CASTRO, ALMEIRA e FERREIRA, 2010; SANTOS, 2012).

Às instituições cabe a organização da educação especial sob a ótica da educação inclusiva, disponibilizando mecanismos e apoio para que ao aluno seja garantida a oportunidade de ser, de fato, parte integrante da comunidade escolar, nesse contexto, está incluída a disponibilização de profissionais instrutores, intérpretes/tradutores, guias, monitores para auxílio e apoio nas atividades escolares cotidianas dos estudantes (KASSAR, 2011; CASTRO, ALMEIDA e FERREIRA, 2010; CAMARGO, 2017).

A adequação do espaço físico, de recursos pedagógicos e a promoção da acessibilidade também são de competência dos sistemas de ensino. A acessibilidade deve ser garantida por meio da exclusão de qualquer barreira que dificulte o processo do aluno, seja ela física ou de comunicação ou informação (BRASIL, 2007; KASSAR, 2011). 
O educador que deseja atuar na educação especial deve compreender a necessidade da educação continuada e permanente, que vislumbre a educação inclusiva, além da compreensão geral sobre a prática docente, deve estar integrado à prática específica da educação especial, possibilitando sua atuação no atendimento educacional especializado, tanto em salas especiais, quanto em salas de ensino regular, além de estar capacitado a atuar em toda a rede de apoio aos estudantes com necessidades especiais (BRASIL, 2007; CASTRO, ALMEIRA e FERREIRA, 2010; KASSAR, 2011; SANTOS, 2012).

\section{CONSIDERAÇÕES FINAIS}

A cinesia global em prol da educação inclusiva constituí-se de um movimento político, cultural, social e pedagógico, estimulado com intuito de defender o direito dos discentes de estarem aprendendo em conjunto, participando das atividades escolares, sem tipo algum de segregação.

A educação inclusiva constrói um paradigma da educação que se fundamenta na compreensão dos direitos humanos, que trata igualdade e diferença como princípios inseparáveis, caminhando positivamente em direção a um contexto que considera o conceito de equidade, quando se preocupa em resgatar o histórico da exclusão no ambiente escolar e fora dele.

Dentro do universo da educação inclusiva, encontramos a educação especial, que caminha por todas as etapas escolares, sendo responsável por realizar o atendimento especializado ao aluno com necessidade especial, orientando sobre a inserção do aluno em turmas de ensino regular.

O educador que decide ingressar na educação especial deve possuir conhecimento global e específico acerca da docência e, além disso, manter-se atualizado sobre as mudanças e desenvolvimento da área. A atualização permite que o professor esteja interado com os serviços especializados para atendimento de alunos com necessidades especiais e sobre a sua inserção em salas de aula de ensino regular, permite conhecimento sobre acessibilidade e recursos relacionados à área.

E os ambientes formais de ensino tem a responsabilidade de possibilitar meios para que o aluno tenha acesso aos recursos escolares e espaços, bem como, tem a obrigação de traçar estratégias para vencer as barreiras de 
comunicação impostas por algumas deficiências para possibilitarem a desenvolvimento integral do processo de ensino aprendizagem do discente, atendendo assim, a individualidade educacional do aluno. Desta forma, construindo um ambiente inclusivo, tanto físico, quanto pedagógico, para que o aluno com necessidade especial faça parte, de fato, do ambiente escolar.

\section{REFERÊNCIAS}

BATISTA, Marcus Welbi; ENUMO, Sônia R. Fiorim. Inclusão escolar e deficiência mental: análise da interação social entre companheiros. Estudos de Psicologia, Natal, v. 9, n. 1, p. 101-111, 2004

BORGES, Adriana Araújo Pereira. As Classes Especiais e Helena Antipoff: uma Contribuição à História da Educação Especial no Brasil. Rev. bras. educ. espec. [online]. 2015, vol.21, n.3, pp.345-362. ISSN 1413-6538.

BRASIL. Constituição (1988). Constituição da República Federativa do Brasil. Brasília, 1988. Disponível em: <http://www. planalto.gov.br/ccivil_03/constituicao/constituicao.htm>.

BRASIL. Presidência da República. Lei no 9.294, de 20 de dezembro de 1996. Estabelece as diretrizes e bases da educação nacional. Diário Oficial da União, Brasília, 23 dez. 1996.

Ministério da Educação. Secretaria de Educação Especial. Educação infantil - saberes e práticas da inclusão: dificuldades acentuadas de aprendizagem ou limitações no processo de desenvolvimento. Elaboração de Rosana Maria Tristão e Ide Borges dos Santos. Brasília: MEC/SEESP, 2006.

. Ministério da Educação. Secretaria de Educação Especial. Formação continuada a distância de professores para 0 atendimento educacional especializado: deficiência mental. Elaboração de Adriana L. Limaverde Gomes et al. Brasília: MEC/SEED/SEESP, 2007.

. Ministério da Educação. Secretaria de Educação Especial. A educação especial na perspectiva da inclusão escolar: 0 atendimento educacional especializado para alunos com deficiência intelectual. Elaboração de Adriana L. Lima Verde Gomes, Jean-Robert Poulin e Rita Vieira de Figueiredo. Brasília: MEC/SEESP; Fortaleza: UFCE, 2010.

CAMARGO, Eder Pires de. Inclusão social, educação inclusiva e educação especial: enlaces e desenlaces. Ciênc. educ. (Bauru) [online]. 2017, vol.23, n.1, pp.1-6. ISSN 1516-7313.

CARAMORI, Patricia Moralis e DALL'ACQUA, Maria Júlia Canazza. ESTRATÉGIAS PEDAGógICAS EMPREgADAS POR PROFESSORES DE EDUCAÇÃO ESPECIAL AOS SEUS ALUNOS COM DEFICIÊNCIA INTELECTUAL SEVERA: UM ESTUDO DESCRITIVO DA 
PRÁtICA DOCENTE. Rev. bras. educ. espec. [online]. 2015, vol.21, n.4, pp.367-378. ISSN 1413-6538.

CASTRO, José Carlos V.; ALMEIDA, Maria Josilane M.; FERREIRA, Vanessa Queiroz. Os benefícios das intervenções pedagógicas para 0 desenvolvimento cognitivo do estudante com déficit intelectual. Anais das Jornadas de Pós-Graduação da Faculdade Integrada Brasil Amazônia - FIBRA, Belém, n. 3, p. 21-33, set. 2010.

DECRETO 5.884 de 21 de abril de 1933. Revista de Educação, v. 2, 1933.

VIEIRA, Alexandro Braga; RAMOS, Ines de Olievira. Diálogos entre Boaventura de Sousa Santos, Educação Especial e Currículo. Educação \& Realidade, Porto Alegre, v. 43, n. 1, p. 131-151, jan./mar. 2018.

Editorial, Ciênc. Educ., Bauru, v. 23, n. 1, p. 1-6, 2017.

Educar em Revista, Curitiba, Brasil, n. 41, p. 61-79, jul./set. 2011. Editora UFPR 79 PIZZOLI, U. Psychologia Pedagogica. Revista de Ensino. Transcrição autorizada pelo autor do Estado de S. Paulo. Ano XIII, n. 3, dez. 1914.

HARLOS, Franco Ezequiel; DENARI, Fátima Elisabeth ; ORLANDO, Rosimeire Maria. Análise da estrutura organizacional e conceitual da educação especial brasileira (2008-2013). Rev. bras. educ. espec. [online]. 2014, vol.20, n.4, pp.497-512. ISSN 1413-6538. http://dx.doi.org/10.1590/2175-623667534

JANNUZZI, G. A luta pela educação do deficiente mental no Brasil. Campinas, São Paulo: Editores Associados, 1992.

KASSAR, Mônica de Carvalho Magalhães. Educação especial na perspectiva da educação inclusiva: desafios da implantação de uma política nacional. Educar em Revista, Curitiba, Brasil, n. 41, p. 61-79, jul./set. 2011. Editora UFPR

MANTOAN, Maria T. Eglér. Inclusão escolar: 0 que é? Por quê? Como fazer? São Paulo: Moderna, 2006.

RIBEIRO, Sara C. Martins. Inclusão social dos jovens com deficiência mental: o papel da formação profissional. Dissertação (Mestrado) - Escola Superior de Educação de Paula Frassinett, Porto, 2009.

SÁNCHEZ, Pilar Arnaiz. A educação inclusiva: um meio de construir escolas para todos no século XXI. Inclusão: Revista da Educação Especial, Brasília, p. 7-18, out. 2005.

SANTOS, Boaventura de Sousa. A Gramática do Tempo: para uma nova cultura política. São Paulo: Editora Cortez, 2006.

SANTOS, Daisy Cleia Oliveira dos. Potenciais dificuldades e facilidades na educação de alunos com deficiência intelectual. Educ. Pesqui., São Paulo, v. 38, n. 04, p. 935-948, out./dez. 2012.

SASSAKI, Romeu Kazumi. Atualizações semânticas na inclusão de pessoas: deficiência mental ou intelectual? doença ou transtorno mental? Revista Nacional de Reabilitação, São Paulo, ano IX, n. 43, p. 9-10, mar./abr. 2005. 
SOBRINO, Reginaldo Celio; PANTALEÃO, Edson; SÁ, Maria das Graças Carvalho Silva de. O PLANO NACIONAL DE EDUCAÇÃ̃o E A EDUCAÇẢO ESPECIAL. Cadernos de Pesquisa v.46 n.160 p.504-525 abr./jun. 2016

VITTA, Fabiana Cristina Frigieri de; SILVA, Carla Cilene Baptista da; ZANIOLO, Leandro Osni. Educação da Criança de Zero a Três Anos e Educação Especial: uma Leitura Crítica dos Documentos que Norteiam a Educação Básica'. Rev. bras. educ. espec. [online]. 2016, vol.22, n.1, pp.9-26. ISSN 1413-6538.

GIL, A. C. Como elaborar projetos de pesquisa - 4. ed. - São Paulo: Atlas, 2002.

MARCONI, Andrade Marina; LAKATOS, Eva Maria. Técnicas de pesquisa. 7 ed. São Paulo: Atlas, 2009. 